ADALAH : Buletin Hukum \&

Keadilan

Buletin Hukum \& Keadilan

@adalahuinjkt

\title{
Menyongsong Bonus Demografi Indonesia
}

Syarifah Gustiawati Mukri*

Sudah menjadi kewajiban bagi suatu negara untuk melakukan pembangunan generasi mudanya sebagai asset masa depan. Pembangunan itu dapat berupa pembangunan gerakan pemuda, bukan hanya pada level nasional namun juga pada level internasional. Bagi Indonesia sendiri, gerakan tersebut memberikan implikasi semakin pentingnya posisi pemuda dalam konteks bonus demografi sebagai intelectual capital bagi bangsa yang besar.

Bonus demografi merupakan kesempatan emas yang dapat dinikmati suatu negara, sebagai akibat dari besarnya proporsi penduduk produktif rentang usia antara 15 - 40 tahun dalam evolusi kependudukan yang dialaminya. Bonus demografi merupakan masa transisi demografi, yaitu terjadinya penurunan tingkat kematian yang diikuti dengan penurunan tingkat kelahiran dan dapat digunakan untuk meningkatkan pertumbuhan ekonomi dengan memanfaatkan penduduk usia produktif secara optimal. Dengan demikian, bonus demografi akan menjadi kesempatan besar, jika banyaknya penduduk usia produktif seimbang dengan ketersediaan lapangan pekerjaan (Noor, tth: 124).

Jepang pada tahun 1950 pernah mengalami bonus demografi, meskipun mereka telah mengalami

\section{Anak Muda Indonesia, Sudah Siap Menghadapi Bonus Demografi?}

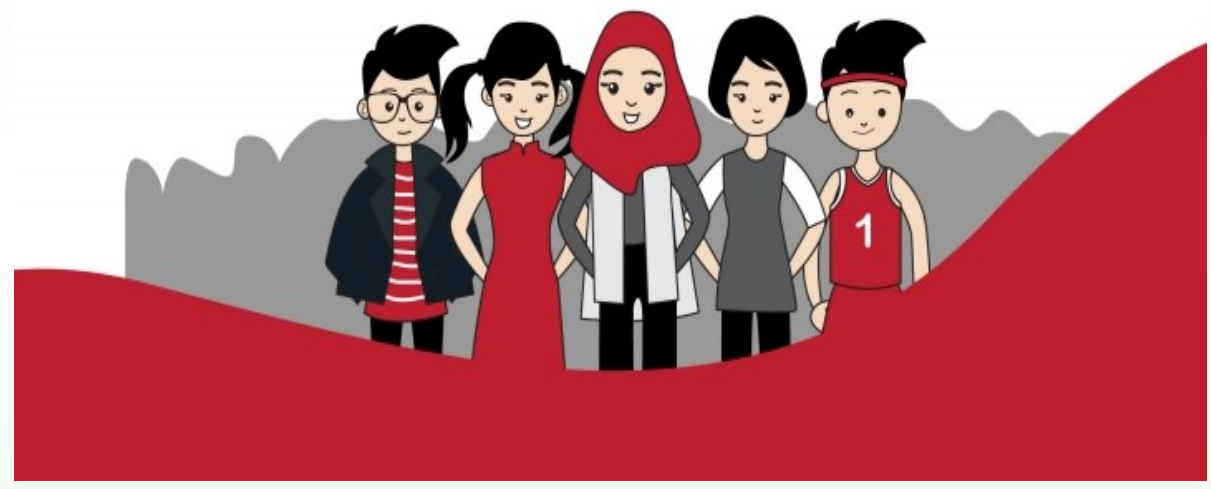

kekalahan dalam perang dunia kedua pada tahun 1945. Sebagaimana Korea pada tahun 1950, mereka disebut sebagai negara termiskin di Asia. Namun akhirnya, Korea mampu bangkit pasca kemiskinan dengan memanfaatkan bonus demografi yang dapat melahirkan ide besar dari kelompok kecil. Demikian pula halnya bangsa Indonesia, harus mempersiapkan diri dalam menghadapi bonus demografi, sehingga bonus usia produktif tersebut tidak menjadi sia-sia, tetapi dapat dirasakan manfaatannya untuk kemajuan bangsa.

Gerakan pemuda ini, secara simultan dilakukan oleh seluruh organisasi kepemudaan bertujuan untuk mewujudkan Indonesia yang berkemajuan. Sehingga, jika dapat dimanfaatkan dengan baik, gerakan ini akan membawa Indonesia mampu bangkit dari kemiskinan, keterbelakangan mental, menjadi salah satu negara yang paling berpengaruh dalam melahirkan ide besar dari komunitas kecil, sebagai poros intectual capital modal dalam pendidikan dan inovasi, sekolah negarawan, dan menjadi bangsa yang disegani.

Bangsa Indonesia diperkirakan mengalami bonus demografi pada tahun 2012-2028. Hal tersebut menjelaskan bahwa Indonesia masih memiliki banyak waktu untuk menyiapkan penduduk usia produktif yang menjadi peran utama dalam pemanfaatan bonus 
demografi. Usia produktif tersebut berkisar 20-30 tahun, di usia tersebut mereka dapat menunjukkan jati dirinya di tingkat nasional. Berdasarkan data kependudukan di Indonesia terdapat 60 juta anak muda dari 200 juta jumlah penduduk Indonesia, kabupaten Bogor saja jumlah penduduknya mencapai 5 juta sedangkan $60 \%$ atau tiga juta dari jumlah total penduduk Bogor adalah anak muda.

Momentum Indonesia dalam memanfaatkan pemuda sebagai calon pemimpin bangsa adalah keniscayaan. Kesempatan tersebut dilakukan secara simultan oleh seluruh organisasi kepemudaan. Pola gerakan bersama yang dapat dilakukan yakni dalam meningkatkan kualitas pemuda melalui peningkatan pendidikan, ketrampilan dan kesehatan, serta kemampuan bangsa dalam menyiapkan lapangan pekerjaan bagi para tenaga kerja sesuai dengan kemampuan pendidikan dan ketrampilan yang dimiliki, sehingga mereka mampu memperoleh pendapatan yang dapat menopang kehidupan diri sendiri dan keluarganya, terutama orang yang menjadi tanggung jawab mereka di usia non produktif. Jadi, untuk mendapatkan hasil pemanfaatan yang maksimal, tidak hanya diperlukan kerja keras oleh organisasi kepemudaan saja, melainkan seluruh komponen kehidupan.

Ketua Pemuda Muhammadiyah Nasihudin Kabupaten Bogor menyatakan bahwa upaya yang dapat dilakukan dalam menghadapi bonus demografi yaitu dengan menciptakan pergerakan dakwah pemuda, selain diperlukan pengembangan sumber daya manusia di bidang dakwah bekerjasama antara PKU (Pendidikan Kader Ulama) dan Organisasi kepemudaan. Perspektif lain disampaikan Irfan Darajat, Ketua Karang Taruna Pemuda Desa Kabupaten Bogor periode tahun 20132018, ia menyatakan bahwa pemuda karang taruna harus kembali ke khittah yaitu kembali ke desa, melaksanakan program pemberdayaan karang taruna tingkat desa, dan fokus pergerakannya di desa, sehingga kegiatan desa dapat terbantu oleh pemuda karang taruna. Sementara hubungannya dengan organisasi pemuda lainnya hanya sebatas jaringan kerja. Sedang Ketua KNPI Kabupaten Bogor Muhammad Burhani menyatakan bahwa langkah awal pergerakan pemuda dengan mempersatukan perbedaan, menggali potensi pemuda, rapat kerja pemuda dan program kepemudaan lainnya. KNPI sebagai fasilitator pemuda berupaya menyamakan visi dan misi komunitas pemuda kemudian bergerak Bersama (Bogor, 31/11/2015).

Indonesia disinyalir memiliki kekuatan ekonomi di dunia 20 tahun ke depan, sedangkan realitas menunjukkan bahwa indeks IPM Indonesia berada diurutan 108 di dunia, sementara di negara Asean Indonesia berada di urutan kelima bahkan di bawah Malaysia. Untuk itu Indonesia harus fokus pada program pembangunan sumber daya manusia, yaitu program menanam manusia untuk 25 tahun ke depan sebagai wujud intelektual capital, dan memanennya 30-40 tahun berikutnya. Program pengembangan potensi sumber daya pemuda tersebut menjadi prioritas untuk kemajuan bangsa, agar lapangan pekerjaan dapat terserap secara optimal. Demikianlah, diantara program yang harus disiapkan. Jika tidak disiapkan, maka bonus demografi ini akan menjadi bencana besar untuk sebuah bangsa yang besar.

\section{Pustaka Acuan:}

*Penulis adalah dosen tetap FAI Universitas Ibn Khaldun (UIKA) Bogor, sekaligus alumni terbaik Pendidikan Kader Ulama (PKU) angkatan IX.

Noor, Munawar, "Kebijakan Pembangunan Kependudukan dan Bonus Demografi", dalam Serat Acitya; Jurnal Ilmiah UNTAG Semarang, (tth).

Simposium Pemuda, "Peran Pemuda Kabupaten Bogor Versus Bonus Demografi", Bogor, 31 Nopember 2015, Kerjasama Lembaga Pengkajian Keagamaan dan Pendidikan Ulama (LPKPU), Majelis Ulama Indonesia (MUI) Kab. Bogor, Alumni Pendidikan Kader Ulama (PKU) Angkatan ke IX, Majelis Belia Malaysia, Komite Nasional Pemuda Indonesia (KNPI) Kabupaten Bogor, Aliansi Pemuda Muhammadiyah, Aliansi Pemuda Karang taruna Kabupaten Bogor.

'Adalah; Buletin Hukum dan Keadilan merupakan berkala ilmiah yang diterbitkan oleh Pusat Studi Konstitusi dan Legislasi Nasional (POSKO-LEGNAS), Fakultas Syariah dan Hukum UIN Syarif Hidayatullah Jakarta.

Penasehat: Prof. Dr. H. Abdul Ghani Abdullah, SH., Prof. Dr. H. A Salman Maggalatung, SH., MH. Pemimpin Redaktur: Indra Rahmatullah, Tim Redaktur: Nur Rohim Yunus, Fathuddin, Mara Sutan Rambe, Muhammad Ishar Helmi, Erwin Hikmatiar. Penyunting: Latipah, Siti Nurhalimah. Setting \& Layout: Siti Romlah 